\title{
Foreword
}

\section{A Bit of History}

I shall never forget our first meeting. I was Director at the Centre for English Language Education (CELE) at the University of Nottingham, a role I took over in 1991. The Centre's administrative assistant tapped on my office door one day and announced a visitor who had slightly alarmed her. She told me a big American man in motorbike leathers was hoping to talk to me. I popped my head out and, sure enough, a tall, muscular figure was striding down the corridor towards my room, leather-clad, crashhelmet under his arm. Evel Knievel? Terminator? Not really. With a warm smile, Norbert Schmitt introduced himself. At that time, Norbert had already left behind his farming background, had decided on an academic future and was keen to study the acquisition of English vocabulary with a view to a doctorate. He was, so to speak, doing the rounds, testing the waters to see if and where anyone shared his interests. I am delighted to say he chose Nottingham and completed his PhD in 1997.

It may seem strange to the ears of younger readers to be told that, in the early 1990s, vocabulary had not by any means fully morphed out of its 'Cinderella' status in language teaching and learning, the decades of 'unredeemed neglect' that Ron Carter and I complained of in 1988 (Carter \& McCarthy, 1988: 41). If I may be forgiven a brief historical excursion, it is worth dwelling on this point, as it explains so much of the nature of the environment in which Norbert Schmitt's vocabulary work began and took root, and the immense contributions Norbert has made to the field ever since.

Carter and I were writing at the tail end of a long era during which structuralism, with its emphasis on syntax and phonology, had prevailed in foreign and second language teaching. Although the great pioneer of our applied linguistic profession Harold Palmer had, in the earlier part of the 20th century, put forward a set of systematic principles for the teaching of vocabulary, referring to himself in 1936 as being in 'a state of revolt against the giving to pupils as a first vocabulary any haphazard assortment of words, as if taken at random out of a sack' (Palmer, quoted in Smith, 1999: 36), Palmer's heritage was seen mostly in his emphasis on pronunciation, grammar and structural drilling, as manifested in his 
works published in the immediate aftermath of the First World War (Palmer, 1922, 1924).

One vestige of the structuralist heritage was seen in the situational syllabuses that threaded through the pedagogical fabric of the 1960s and later, which Mitchell criticised: such syllabuses offered 'little more language than the learning by heart of situationally relevant phrases and vocabulary, and failed to lead the learner systematically to linguistic independence and creativity' (Mitchell, 1994: 35-36). The communicative movement, ushered in in the 1970s, in its strongest versions did not help either: it was assumed in many circles that linguistic needs (grammar, vocabulary) would be met as they emerged during the practice of communicative utterances - language as 'doing'. The notion of an organised vocabulary syllabus or an understanding of the psycholinguistic dimension of vocabulary acquisition had low priority (McCarthy, 1984; Mitchell, 1994: 36).

That is not to say there were no voices crying in the wilderness. Most notably, Jack Richards (1976) struck a new chord in considering psycholinguistic and sociolinguistic questions to be germane to the notion of lexical competence. Richards asserted that the question of 'knowing' a word involved not only the syntactic and derivational features of a word but also the problem of how words are remembered, and word knowledge necessarily embraced psychological and social dimensions such as word association and functional and situational use. This inclusive approach, based neither entirely in descriptive linguistics nor entirely in psycholinguistics or sociolinguistics, mapped out territory for a potentially greatly expanded world of research in vocabulary studies. Richards' conclusion, at a time when vocabulary was in the pedagogical doldrums, was that 'beyond the elementary levels of instruction, a major feature of a second language program should be a component of massive vocabulary expansion' (Richard, 1976: 84).

Richards' paper was followed by another in TESOL Quarterly on the subject of vocabulary instruction, by Elliott Judd (Judd, 1978). This article too challenged the neglected status of vocabulary in second language pedagogy and questioned the assumption that vocabulary teaching and learning should be swallowed up in reading and listening classes and the parallel belief that vocabulary expansion should only be a concern once the basics of syntax were under control. Judd argued for vocabulary knowledge to be taught as a skill per se and that vocabulary teaching should be commenced at an early stage in a course of instruction. Properly organised, direct vocabulary teaching would avoid the 'randomized appearance of vocabulary' (1978: 73), a criticism that echoed Palmer's metaphor of plucking vocabulary at random out of a sack.

Anne-Marie Cornu (1979), in a paper emanating from the Katholieke Universiteit te Leuven, Belgium, offered another important, though perhaps now undervalued, contribution to the debate. Cornu advocated a 
semantic field approach to vocabulary and at the same time recognised the need for psycholinguistic understanding with regard to the problem of vocabulary retention, concluding that vocabulary learning could not just be 'the assimilation of lists of words' (Cornu, 1979: 272). This approach was continued by Joanna Channell (1981) and later by another Louvain scholar, Ludo Beheydt (Beheydt, 1987).

\section{The (Re)birth of Vocabulary Study}

One figure whose presence has been felt in our field for a very long time and whose work influenced Norbert Schmitt (and most of us) profoundly is Paul Meara. Meara (1980) is an article considered to represent a launchpad for the research agenda in second language vocabulary acquisition studies which Norbert and so many after him have embraced. Seen from the perspective adopted by Ronald Carter and me in our work on vocabulary, Meara's work was strikingly different. For Carter and me, the 1980s was indeed a period of ferment in the study of vocabulary and language teaching and learning. But we were more interested in the role of linguistic description in the understanding of the lexicon, spurred on by our mentor John Sinclair, whose corpus linguistic research was giving empirical substance to Firthian notions of meaning in context, collocation and chunking, an inspiration which I hope was reflected in our 1988 book. I had also around that time become interested in discourse analysis under Sinclair's guidance, and I advocated a more discourse-sensitive approach to lexical meaning and function and how it might be applied to Englishas-a-Foreign-Language (EFL) vocabulary teaching (McCarthy, 1984). Meara took a different line, one that was to have greatly different consequences.

Meara was interested in acquisition, an aspect of vocabulary study which, he pointed out, had been given 'short shrift from applied linguistics' (Meara, 1980: 221). And his comment on the type of statisticaldescriptive work on frequency, which at the time was becoming facilitated by developments in computing, placed him in stark contrast to what I have described as the approach taken by Carter, myself and others enamoured of the burgeoning field of corpus linguistics: 'this work is characteristic in that it concentrates on what is basically a problem to do with the management of learning, rather than with the learning process itself - i.e. the object of this type of research is to decide what words are to be taught, not to find out how words are actually learned' (Meara, 1980: 224). He had a point.

Among the issues which needed addressing for Meara were vocabulary size (just how many words can learners acquire in a given time, and is there an upper limit?), the need to understand 'the complex patterns of meaning relationships that characterise a proper, fully formed lexicon, as opposed to a mere word list' (1980: 225), the implementation of proper 
longitudinal studies, the absorption of words over time into the learner's lexicon, the role of bilingualism in assisting our understanding of second language learners, especially on the question of storage in the mental lexicon, the sematic relations between words, word association and how the formal aspects of words are acquired (Meara \& Ingle, 1986). This was a research agenda vast enough to preoccupy a century of researchers - it has impressively remained current for almost half of one - and it led Meara to reflect just over a decade later that studies of vocabulary acquisition had mushroomed and that it was almost impossible to keep up with the field even if you did nothing else (Meara, 1995). We should remember that much of the content of the present volume, representing as it does the voices of a well-established research community, in the 1980s would have been revolutionary.

The early 1980 s saw the emergence on to the vocabulary studies scene of another giant on whose shoulders Norbert has been proud to stand: Paul Nation. Nation (1982) is another of those landmark papers which anyone interested in vocabulary teaching and learning should read. Distinguishing between indirect and direct vocabulary learning, Nation asks pertinent questions which at that time were not at the top of the profession's research agenda: 'How does indirect learning of vocabulary by reading compare with and complement indirect learning by listening? Are vocabulary exercises which directly teach the production of vocabulary in speaking and writing more sure and efficient in developing a productive vocabulary than indirect learning? Is directly learned vocabulary retained in the memory for a longer time than indirectly learned vocabulary?' (Nation, 1982: 15). The paper also looks at learning word pairs (L2 words and their L1 translation equivalents) in relation to the number of encounters with them and their retention, and the most efficient ways of dividing up the learning task, as well as addressing the question of word difficulty, and challenging the belief that words should always be taught in context. Nation concluded by warning against inadequate control of variables in experimentation and called for future research to approach vocabulary learning 'with a richer idea of what it means to know a word and of how words are learned' (Nation, 1982: 32). The breadth and depth of Nation's work is best appreciated in his 2001 book, where we see not only the psycholinguistic preoccupations rehearsed in the 1982 paper treated in detail but also an awareness of the significant role of description in bringing to light the phenomena of chunking and collocation, as well as formal aspects of affixation in his work with Bauer (Bauer \& Nation, 1993; Nation, 2001).

What we see as the 1980s draw to a close is a head of steam propelling concerns with the place of vocabulary in language teaching and learning and dissatisfaction over its perceived neglect. This was the world that Norbert Schmitt entered: vocabulary description, vocabulary teaching and vocabulary acquisition, all rubbing shoulders in the post-structuralist world. How was he to make sense of its almost chaotic complexity? 


\section{Seeing the Wood for the Trees}

A short preface like this one can scarcely do justice to Norbert Schmitt's ability to immerse himself in the dynamic and multipronged research agenda that had been established in the 1980s in lexical description and second language lexical acquisition and pedagogy - an agenda necessarily only briefly outlined in the previous sections. Norbert's total immersion in this milieu, with its attendant danger of prompting a butterfly existence in research, hopping from one promising bloom to another, in fact led him to forge a rigorous pathway combining the best of description with a profound understanding of the issues involved in acquisition while never losing sight of the practical world of vocabulary teaching.

It is not the purpose of this preface to survey Norbert's work. The plentiful references to it in the chapters of this book provide more than an adequate paean to his achievements. Here, I will simply point to a few of his studies in an attempt to capture the character and breadth of his research.

With his wife, Diane, Norbert compiled a list of vocabulary learning strategies which, in my opinion, has not been surpassed, an account of which may be found in Schmitt and Schmitt (1993) and further in Schmitt (1997). Apart from providing the full catalogue of strategies, the survey of learners' reactions to them provide some surprises, with things in vogue at the time (e.g. the keyword approach, word imaging, group work on words) scoring poorly. The study characterised Norbert's attention to method and control of detail, even in this 'early' work. He is not, and has never been, one to rush to conclusions without careful thought and deliberation. The other feature of the 1993 paper which, for me, is the hallmark of Norbert's philosophy, is his willingness and ability to collaborate.

Norbert and I worked together on an edited book (Schmitt \& McCarthy, 1997) and, although I had supervised his PhD at Nottingham, like all good doctoral students, he had soon overtaken his mentor in knowledge and vision. We wanted our book to represent that research agenda which the 1980s had thrown up and which is described in this preface. Norbert had no difficulty navigating and editing the descriptive sections, where the growing influence of corpus linguistics came to the fore, but equally handled with aplomb the chapters on vocabulary acquisition and pedagogy and was able to see connections across the sections of the book and to tease out recurrent themes which my lazy brain had missed. Norbert always seemed to be able to see the wood for the trees. One of his great talents has always been the ability to make sense of formal descriptive issues and see their connections and relevance to language learners, as seen, for example, in his collaboration with Cheryl Boyd Zimmerman in their study of learners' grasp of derivational word forms (Schmitt \& Zimmerman, 2002). 
Nottingham provided an ideal environment for Norbert in many ways (a situation that was ideal for Ron Carter and me, too, in that we held on to Norbert, who became a valued colleague). We already had a solid tradition of descriptive vocabulary studies in the work of Ron Carter and Joanna Channell, we were building spoken corpora and we wanted to use our expertise and resources to explore the role and status of lexis in language learning and teaching. Carter and I had become interested in chunks or formulaic sequences, which seemed to be ubiquitous in our corpus data. Norbert immediately saw the profound implications of formulaic sequences, and his 2004 edited book on the subject covers not only the full range of research in the field but shows the breadth of Norbert's knowledge in the area in the fact that he co-authored four of the chapters, a truly remarkable achievement (Schmitt, 2004). Once again, the work takes on the imperatives of the 1980s research agenda but enhances the exegesis with the latest developments in corpus linguistics, psycholinguistic underpinning and sociocultural theory.

If one could summarise Norbert's approach in a few words, it would be that his intense curiosity about language learning, born of his years as a language teacher in Japan, has kept human subjects at the forefront of his investigations of questions of vocabulary. Not content with the mechanistic output of corpus frequency lists, his work with Bruce Dunham (Schmitt \& Dunham, 1999) explores native and non-native speakers' intuitions of word frequency, with some fascinating and insightful results delivered with characteristic caution and modesty.

As mentioned, a central feature of Norbert's research has always been collaboration and, in later years, the nurturing of the next generation of scholars in the field of vocabulary studies. The present volume bears witness to the profound respect with which his colleagues, associates and former students around the world regard him. He is one of the people who has made sure that the great debate of the 1980s over the need to reinvigorate vocabulary teaching and learning has been translated into action in an enduring research agenda which continues to push the field forward. In his ability to embrace and grasp the two worlds of description and acquisition and to see what they mean in relation to each other and to pedagogy, he is a man for all seasons. I am privileged to know him as supervisor, colleague and friend.

Michael McCarthy

Cambridge, June 2020

\section{References}

Bauer, L. and Nation, P. (1993) Word families. International Journal of Lexicography $6(4), 253-279$.

Beheydt, L. (1987) The semantization of vocabulary in foreign language learning. System $15(1), 55-67$. 
Carter, R.A. and McCarthy, M.J. (1988) Vocabulary and Language Teaching. Harlow: Longman.

Channell, J. (1981) Applying semantic theory to vocabulary teaching. ELT Journal XXXV (2), 115-122.

Cornu, A.-M. (1979) The first step in vocabulary teaching. The Modern Language Journal $63(5 / 6), 262-272$.

Judd, E.L. (1978) Vocabulary teaching and TESOL: A need for reevaluation of existing assumptions. TESOL Quarterly 12 (1), 71-76.

McCarthy, M.J. (1984) A new look at vocabulary in EFL. Applied Linguistics 5 (1), $12-22$.

Meara, P. (1980) Vocabulary acquisition: A neglected aspect of language learning. Language Teaching 13 (3-4), 221-246.

Meara, P. (1995) Editorial: Single-subject studies of lexical acquisition. Second Language Research 11 (2), i-iii.

Meara, P. and Ingle, S. (1986) The formal representation of words in an L2 speaker's lexicon. Second Language Research 2 (2), 160-171.

Mitchell, R. (1994) The communicative approach to language teaching: An introduction. In A. Swarbrick (ed.) Teaching Modern Languages (pp. 33-42). London: Routledge.

Nation, I.S.P. (1982) Beginning to learn foreign vocabulary: A review of the research. RELC Journal 13 (1), 14-36.

Nation, I. (2001) Learning Vocabulary in Another Language. Cambridge: Cambridge University Press.

Palmer, H.E. (1922) The Oral Method of Teaching Languages. Cambridge: W. Heffer and Sons Ltd.

Palmer, H.E. (1924) A Grammar of Spoken English on a Strictly Phonetic Basis. Cambridge: W. Heffer and Sons Ltd.

Richards, J.C. (1976) The role of vocabulary teaching. TESOL Quarterly 10 (1), 77-89.

Schmitt, N. (1997) Vocabulary learning strategies. In N. Schmitt and M. McCarthy (eds) Vocabulary: Description, Acquisition and Pedagogy (pp. 199-227). Cambridge: Cambridge University Press.

Schmitt, N. (ed.) (2004) Formulaic Sequences. Amsterdam: John Benjamins.

Schmitt, N. and Dunham, B. (1999) Exploring native and non-native intuitions of word frequency. Second Language Research 15 (4), 389-411.

Schmitt, N. and McCarthy, M. (eds) (1997) Vocabulary: Description, Acquisition and Pedagogy. Cambridge: Cambridge University Press.

Schmitt, N. and Schmitt, D.R. (1993) Identifying and assessing vocabulary learning strategies. Thai TESOL Bulletin 5 (4), 27-33.

Schmitt, N. and Zimmerman, C. (2002) Derivative word forms: What do learners know? TESOL Quarterly 36 (2), 145-171.

Smith, R.C. (1999) The Writings of Harold E. Palmer: An Overview. Tokyo: Hon-no-Tomosha. 